\title{
Asymmetric Photocatalytic C-H Functionalization of Toluene and Derivatives
}

\author{
Daniele Mazzarella, $^{\dagger}$ Giacomo E. M. Crisenza, ${ }^{\dagger}$ and Paolo Melchiorre ${ }^{* \dagger, \downarrow}{ }^{\dagger}$ \\ ${ }^{\dagger}$ ICIQ - Institute of Chemical Research of Catalonia, the Barcelona Institute of Science and Technology, Avinguda Països Catalans \\ 16, 43007 Tarragona, Spain \\ ${ }^{*}$ ICREA - Passeig Lluís Companys 23, 08010 Barcelona, Spain
}

Supporting Information

\begin{abstract}
Reported herein is a visible-light-mediated organocatalytic direct $\mathrm{C}-\mathrm{H}$ functionalization of toluene derivatives to afford enantioenriched $\beta$-benzylated aldehydes from the corresponding enals. The process combines the oxidative power of a chiral excited-state iminium ion and the basic nature of its counteranion to trigger the generation of benzylic radicals by means of a sequential multisite proton-coupled electron transfer mechanism. This study shows that feedstock chemicals generally used as solvents, such as toluene and xylene derivatives, can be used as substrates for making chiral molecules with high enantioselectivity.
\end{abstract}

$\mathrm{T}$ here is high demand for catalytic carbon-carbon bondforming methods that use abundant chemical feedstocks to generate added-value compounds. ${ }^{1}$ Particularly useful is the direct $\mathrm{C}-\mathrm{H}$ functionalization of petroleum-derived raw materials obtained from the production of gasoline by catalytic reformation, ${ }^{2}$ such as toluene and xylenes. Despite the synthetic potential of metal-based $\mathrm{C}-\mathrm{H}$ activation strategies to directly functionalize unactivated substrates, ${ }^{3}$ there are few reported examples of oxidative insertion of transition metal catalysts into primary benzylic $\mathrm{C}\left(\mathrm{sp}^{3}\right)-\mathrm{H}$ bonds (Figure 1a, left arrow). ${ }^{4}$ This is mainly because of the reluctance of primary carbons to undergo $\mathrm{C}-\mathrm{H}$ insertion ${ }^{5}$ and the challenge of regioselectively differentiating a $\mathrm{C}\left(\mathrm{sp}^{3}\right)-\mathrm{H}$ from a $\mathrm{C}\left(\mathrm{sp}^{2}\right)-$ $\mathrm{H}$ bond during the oxidative addition. ${ }^{6}$ Another useful strategy for the functionalization of toluene derivatives relies on radical reactivity and capitalizes upon the different bond dissociation energies (BDE) between the benzylic $\mathrm{C}\left(\mathrm{sp}^{3}\right)-\mathrm{H}$ and the $\mathrm{C}\left(\mathrm{sp}^{2}\right)-\mathrm{H}$ bond. The resulting processes are elicited by thermal $^{7 \mathrm{a}-\mathrm{c}}$ or photochemical ${ }^{7 \mathrm{~d}, \mathrm{f}}$ hydrogen atom transfer (HAT) mechanisms, which generate benzylic radicals from unfunctionalized substrates (Figure 1a, right top arrow). Recently, the utility of this radical pattern was further expanded using aphotoredox catalyst that can oxidize toluene derivatives upon single-electron transfer (SET, Figure 1a, right bottom arrow). ${ }^{8}$

Despite these advances, the direct asymmetric catalytic $\mathrm{C}-\mathrm{H}$ functionalization of toluene and its derivatives remains a challenging target. The literature contains just one reported attempt to use toluene in an enantioselective process. This provided the corresponding product as the minor component of a complex mixture. ${ }^{9 a}$ In addition, an example of stereo-

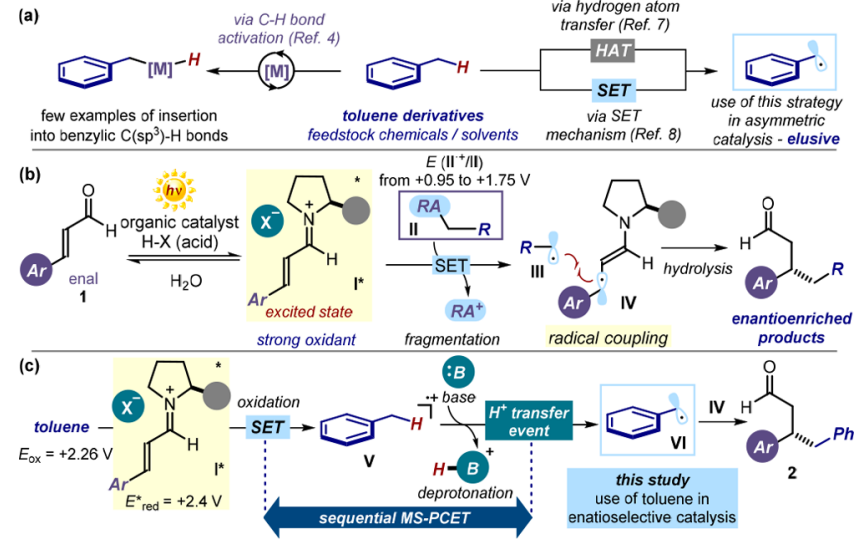

Figure 1. (a) Previous strategy for the direct functionalization of toluene. (b) Our previous study demonstrating that light excitation turns iminium ions I into chiral oxidants, and the resulting SET-based mechanism for generating radicals from easily oxidizable precursors II bearing a redox auxiliary (RA). (c) Proposed approach for the direct asymmetric $\mathrm{C}-\mathrm{H}$ functionalization of toluene.

selective catalytic $\mathrm{C}-\mathrm{H}$ functionalization of the primary carbon in electron-rich toluene derivatives was reported. ${ }^{9 b}$ Herein, we describe a photochemical organocatalytic protocol ${ }^{10}$ that addresses this deficit in enantioselective synthesis. We show that feedstock chemicals, which are generally used as solvents ${ }^{11}$ (e.g., toluene and xylene derivatives), can be used as substrates for making chiral molecules with high enantioselectivity.

Recently, our research group reported that the photoexcitation of iminium ions can be used to generate, and then stereoselectively trap, radicals (Figure $1 \mathrm{~b}$ ). ${ }^{12}$ The iminium ion I, generated upon condensation of an aromatic enal $\mathbf{1}$ with a chiral organocatalyst, can absorb visible light. Selective excitation with a violet-light-emitting diode (LED) turns I into a strong oxidant $\left(\mathrm{I}^{*}\right)$, as implied by its reduction potential, which was estimated as $\approx+2.4 \mathrm{~V}\left(E^{*}{ }_{\text {red }}\left(\mathrm{I}^{*} / \mathbf{I}^{-}\right)\right.$vs $\mathrm{Ag} / \mathrm{Ag}^{+}$in $\left.\mathrm{CH}_{3} \mathrm{CN}\right) .{ }^{12 \mathrm{a}}$ Thus, $\mathrm{I}^{*}$ could trigger the formation of radicals through SET oxidation of a variety of redox partners II. The radical precursors II were purposely adorned with redox auxiliary groups, ${ }^{13}$ including silane ${ }^{12 a}$ and trifluoroborate moieties, ${ }^{12 \mathrm{~b}}$ to facilitate their SET oxidation by imparting a relatively low reduction potential $\left(E_{\text {red }}\left(\mathbf{I I}^{++} / \mathbf{I I}\right)\right.$ ranging from

Received: May 24, 2018

Published: June 22, 2018 
Table 1. Optimization Studies ${ }^{a}$

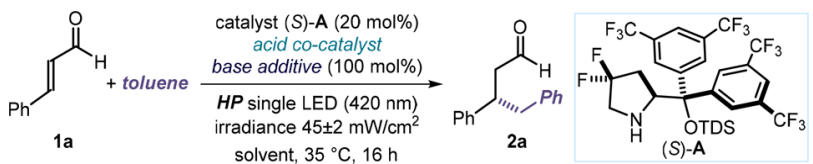

\begin{tabular}{|c|c|c|c|c|c|}
\hline entry & solvent & acid ( $\mathrm{mol} \%)$ & base & yield $(\%)^{b}$ & ee $(\%)^{c}$ \\
\hline $1^{d}$ & toluene & TFA (40) & 2,6-lutidine & & \\
\hline $2^{d}$ & toluene & TFA (40) & $\mathrm{DBPNBu}_{4}$ & & \\
\hline $3^{d}$ & toluene & TFA (40) & $\mathrm{CF}_{3} \mathrm{CO}_{2} \mathrm{~K}$ & 12 & 60 \\
\hline $4^{d}$ & toluene & TFA (40) & none & 19 & 60 \\
\hline 5 & $\mathrm{CH}_{2} \mathrm{Cl}_{2}$ & TFA (40) & none & 30 & 75 \\
\hline 6 & $\mathrm{CH}_{2} \mathrm{Cl}_{2}$ & TfOH (40) & none & & \\
\hline 7 & $\mathrm{CH}_{2} \mathrm{Cl}_{2}$ & DPP (40) & none & & \\
\hline 8 & $\mathrm{CH}_{2} \mathrm{Cl}_{2}$ & $\mathrm{Zn}\left(\mathrm{CF}_{3} \mathrm{CO}_{2}\right)_{2}(40)$ & none & traces & \\
\hline $9^{e}$ & $\mathrm{CH}_{2} \mathrm{Cl}_{2}$ & $\mathrm{Zn}(\mathrm{OTf})_{2}(50)$ & none & $65(63)$ & 83 \\
\hline $10^{e, f}$ & $\mathrm{CH}_{2} \mathrm{Cl}_{2}$ & $\mathrm{Zn}(\mathrm{OTf})_{2}(50)$ & none & $52(51)$ & 83 \\
\hline $11^{e, g}$ & $\mathrm{CH}_{2} \mathrm{Cl}_{2}$ & $\mathrm{Zn}(\mathrm{OTf})_{2}(50)$ & none & 53 & 82 \\
\hline $12^{e, h}$ & $\mathrm{CH}_{2} \mathrm{Cl}_{2}$ & $\mathrm{Zn}(\mathrm{OTf})_{2}(50)$ & none & 28 & 81 \\
\hline
\end{tabular}

${ }^{a}$ TDS, thexyl-dimethylsilyl; TfOH, triflic acid, DPP, diphenyl phosphate; reactions performed at $35{ }^{\circ} \mathrm{C}$ on a $0.1 \mathrm{mmol}$ scale in $0.3 \mathrm{~mL}$ of solvent using 10 equiv of toluene under illumination by a (HP) LED $\left(\lambda_{\max }=420 \mathrm{~nm}\right) .{ }^{b}$ Yield of 2 a determined by ${ }^{1} \mathrm{H}$ NMR analysis of the crude mixture using trichloroethylene as the internal standard; yields of the isolated $\mathbf{2 a}$ are reported in brackets. ${ }^{c}$ The ee of $\mathbf{2 a}$ determined by HPLC analysis. ${ }^{d}$ Performed in $0.4 \mathrm{~mL}$ of toluene. ${ }^{e} 48$ h. ${ }^{f_{1} \mathrm{mmol} \text { scale, } 60 \mathrm{~h} .{ }^{g}} 5$ equiv of toluene. ${ }^{h_{1}} 1$ equiv of toluene.

+0.73 to $+1.74 \mathrm{~V}$ vs $\mathrm{Ag} / \mathrm{Ag}^{+}$in $\left.\mathrm{CH}_{3} \mathrm{CN}\right) .{ }^{12 \mathrm{a}}$ The redox auxiliary group also ensured a rapid irreversible fragmentation of the resulting radical cation $\mathbf{I I}^{++}$(not shown in Figure $1 \mathrm{~b}$ ), which is critical to hamper an unproductive back-electron transfer (BET) and trigger the generation of radicals III. Intermediate III is then stereoselectively intercepted by the chiral $\beta$-enaminyl radical IV, which emerges from the SET, to afford the enantioenriched $\beta$-alkylated aldehyde product.

We wondered if a similar photochemical mechanism could serve to trigger more energy-demanding transformations, such as the direct oxidation of unactivated benzyl substrates, lacking any redox auxiliary group (Figure 1c). In consonance with this scenario, the electrochemical properties of toluene $\left(E_{\mathrm{ox}}=\right.$ $+2.26 \mathrm{~V}$ vs SCE $)^{14}$ suggest that the SET oxidation from the excited iminium ion $\mathbf{I}^{*}$ is thermodynamically feasible. This event would generate the radical cation $\mathbf{V}$, thus increasing the acidity of the benzylic $\mathrm{C}\left(\mathrm{sp}^{3}\right)-\mathrm{H}$ bond ( $\mathrm{pKa}$ of $\mathbf{V}$ estimated as -13 in $\left.\mathrm{CH}_{3} \mathrm{CN}\right) .^{15}$ We envisioned that a base could make the deprotonation step rapid enough to avoid the BET, ultimately affording the benzyl radical VI from toluene. Mechanistically, this path falls under the definition of sequential multisite proton-coupled electron transfer (MS-PCET), ${ }^{16}$ where an electron and a proton are sequentially delivered from toluene to two separate acceptors: the excited-state iminium ion $I^{*}$ and a base. This mechanism offers the benefit to independently modulate both the redox properties of the oxidant $I^{*}$ and the basicity of the additive, facilitating the overall radical formation. The final radical coupling event, governed by IV, would afford the enantioenriched $\beta$-benzylated product 2 using toluene as the alkylating agent.

The feasibility of the plan was evaluated by exploring the reaction of cinnamaldehyde $\mathbf{1}$ a catalyzed by the gemdifluorinated diarylprolinol silylether A (Table 1). The experiments were conducted in toluene, serving as both solvent and substrate, under irradiation by a single high-power (HP) LED $\left(\lambda_{\max }=420 \mathrm{~nm}\right)$ with an irradiance of $45 \mathrm{~mW} / \mathrm{cm}^{2}$ (full details of the setup are reported in Figure S3). The use of organic bases, such as 2,6-lutidine and tetrabutylammonium dibutyl phosphate $\left(\mathrm{DBPNBu}_{4}\right)$, which should facilitate the benzyl radical formation, did not provide any trace of product 2a (entries 1 and 2). The lack of reactivity is a consequence of the neutralization of trifluoroacetic acid (TFA), an additive which is essential to promoting the iminium ion formation. Aware that the coexistence of a base with TFA was crucial, we used potassium trifluoroacetate $\left(\mathrm{CF}_{3} \mathrm{CO}_{2} \mathrm{~K}\right)$ to maintain a constant amount of TFA in solution. Product $2 \mathbf{a}$ was obtained with low yield and enantioselectivity (entry 3). A control experiment in the absence of $\mathrm{CF}_{3} \mathrm{CO}_{2} \mathrm{~K}$ provided similar results (entry 4), suggesting that trifluoroacetate (the counteranion of the iminium $\mathbf{I}$, green circle in Figure $1 \mathrm{~b}, \mathrm{c}$ ), generated upon condensation of the aminocatalyst with $1 \mathrm{a}$, serves as the actual base ${ }^{17}$ responsible for the benzyl radical generation. The use of dichloromethane as solvent provided slightly improved results (entry 5, 10 equiv of toluene were used). We then modulated the strength of the basic counteranion by using acids other than TFA $\left(\mathrm{p} K_{\mathrm{a}}=0.23\right.$ in $\left.\mathrm{H}_{2} \mathrm{O}\right)$. Both a stronger and a weaker acid (triflic acid and diphenyl phosphate, $\mathrm{p} K_{\mathrm{a}}=$ -14.7 and +1.9 , respectively) inhibited the reaction (entries 6 and 7), ${ }^{18}$ indicating that only a narrow $\mathrm{pK}_{\mathrm{a}}$ window was suitable for the photochemical alkylation to take place. We reasoned that Lewis acids could provide an additional mean to assist iminium ion formation while generating the required basic counteranion. ${ }^{19}$ Though zinc(II) trifluoroacetate could not efficiently promote the reaction (entry 8), zinc(II) triflate provided the product $2 \mathrm{a}$ with satisfactory yield and ee (entry 9). The reaction also maintained a good efficiency when performed on a synthetically useful scale ( $1 \mathrm{mmol}$, entry 10$)$. Lowering the amount of toluene affected the yield of the process (entries 11 and 12). Control experiments indicated that the Lewis acid cocatalyst, the organic catalyst, and visiblelight irradiation were all essential for the reaction to proceed.

Adopting the optimized conditions described in Table 1, entry 9, we demonstrated the generality of the enantioselective $\beta$-benzylation of enals using toluene and derivatives (Figure 2). We initially demonstrated that the $(R)$ organic catalyst $\mathbf{A}$ secured access to the opposite enantiomer of the product ent2a with comparable yield and enantioinduction. Different aromatic enals 1 bearing both electron-rich and electron-poor 


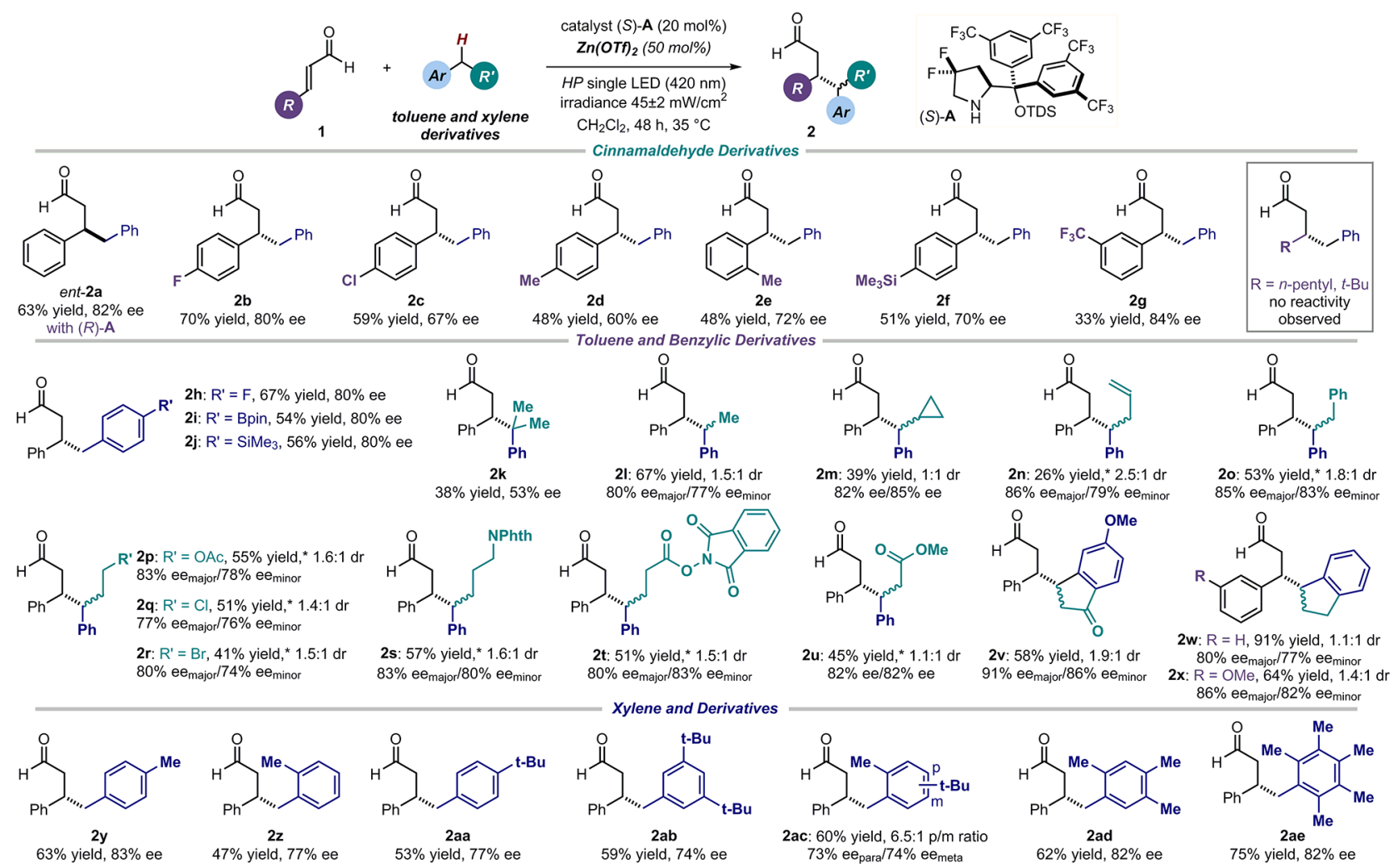

Figure 2. Survey of the enals 1 and the toluene derivatives that can participate in the reaction. Reactions performed on a $0.1 \mathrm{mmol}$ scale using 10 equiv of toluene derivatives in $0.3 \mathrm{~mL}$ of $\mathrm{CH}_{2} \mathrm{Cl}_{2}$. Yield and ee refer to isolated products (average of two runs per substrate). The reactions with xylene derivatives, to afford products $2 y-2 a e$, were performed using trichloroacetic acid $(100 \mathrm{~mol} \%)$ instead of zinc triflate. * Using 5 equiv of benzylic derivatives.

substituents at the phenyl ring effectively participated in the enantioselective functionalization of toluene (products $\mathbf{2 b}-\mathbf{g}$ ). Conversely, aliphatic enals, including tert-butylacroleine and (E)-2-octenal, remained unreacted. The methodology tolerates a wide range of toluene derivatives bearing different functional groups. For example, both pinacolboranyl (2i) and trimethylsilyl (2j) moieties survive the reaction conditions. A tertiary benzylic position can be functionalized to deliver quaternary carbons, although in moderate enantioselectivity (2k), while secondary benzylic derivatives react smoothly in good yields and enantioselectivity but in low diastereomeric ratio (adducts $\mathbf{2 l - x}$ ). The reaction is selective for the benzylic position, because oxidizable moieties, including cyclopropyl (2m) and allyl (2n) groups, remain untouched. Substrates that bear potentially sensitive moieties toward polar or radical processes $(2 \mathbf{p}-\mathbf{u})$ can be selectively functionalized at the benzylic position. Interestingly, the reaction provides for the functionalization of carbonyl compounds with an umpolung pattern (adducts $\mathbf{2 u}$ and $\mathbf{2 v}$ ). Indane proved particularly reactive as a benzylic coupling partner (adduct $2 \mathbf{w}$ ), enabling the participation of the less reactive 3-methoxycinnamaldehyde (2x). When using more elaborated substrates, as for the reactions delivering compounds $\mathbf{2 n}-\mathbf{u}$, the amount of benzylic partner could be lowered to 5 equiv without affecting efficiency and stereoselectivity.

Electron-deficient toluene derivatives did not participate in the reaction because of the increased oxidation potential, while the photochemical asymmetric functionalization of the more electron-rich xylene derivatives required the use of a stronger conjugate base. Trichloroacetic acid (100 mol \%) smoothly afforded the corresponding $\beta$-benzylated products $(2 \mathbf{y}-\mathbf{a e})$.

To demonstrate its synthetic utility, we applied our photochemical protocol to the direct $\mathrm{C}-\mathrm{H}$ functionalization of a pharmaceutically relevant compound. As shown in Scheme 1, (S)-ibuprofen methyl ester 3 was stereoselectively coupled

Scheme 1. Selective Functionalization of a Pharmaceutical Derivative

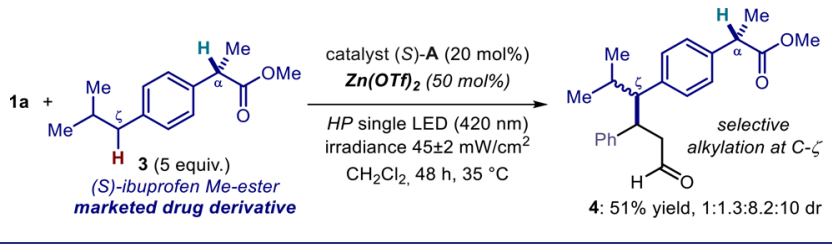

with 1 a to exclusively afford the C- $\zeta$-alkylated product 4 in $51 \%$ yield with moderate diastereoselectivity. No substitution at the tertiary carbon $\mathrm{C}-\alpha$ was observed, thus preserving the original stereochemical information within 3 . $^{20}$

To glean further insights into the mechanism, we used 4ethyltoluene 5, a substrate bearing both a primary and a secondary reactive site, for the alkylation of $1 \mathrm{a}$ in the presence of different acid cocatalysts (Scheme 2 ). The process led to the formation of the regioisomeric products $6 \mathrm{~A}$ and $6 \mathrm{~B}$. A correlation between the site selectivity and the nature of the conjugate base was observed: the stronger the conjugate base, the lower the regioisomeric ratio (6A/6B ratio). This correlation indicates that, in the deprotonation of the benzyl radical cation $\mathbf{V}$ (Figure 1c), an increased strength of the 
Scheme 2. Demonstration that the Strength of the Conjugate Base (the iminium counter-anion) Influences the Regioselectivity and Is Therefore the System's Active Base

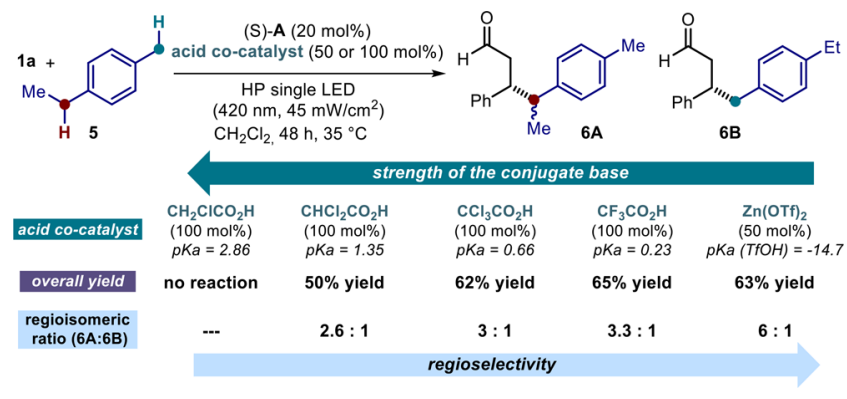

conjugate base lowers the ability to discriminate between the primary and the secondary site, which leads to the thermodynamically more stable radical (BDEs for toluene and ethylbenzene are 368 and $357 \mathrm{~kJ} \mathrm{~mol}^{-1}$, respectively). ${ }^{21}$ These experiments are consonant with the conjugate base of the acid cocatalyst (i.e., the counteranion of the iminium ion) being the active base in the system. In addition, we measured a kinetic isotope effect of $2.0\left(k_{\mathrm{H}} / k_{\mathrm{D}}\right)$ when performing the model reaction using toluene- $d_{8}$. Overall, these data are consistent with a sequential multisite PCET mechanism of benzylic $\mathrm{C}-\mathrm{H}$ bond activation where the deprotonation of the benzyl radical cation $\mathbf{V}$ is the first irreversible step.

On the basis of these experiments and of our previous reports, ${ }^{12}$ a plausible mechanism is depicted in Figure 3. The

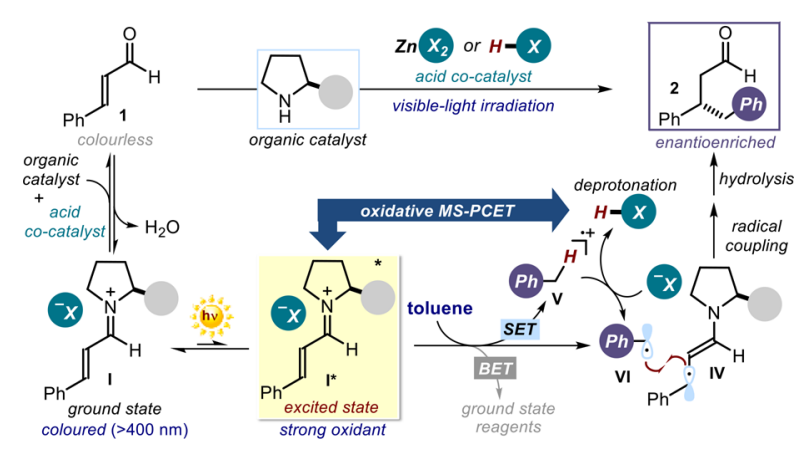

Figure 3. Mechanistic proposal.

acid cocatalyst assists the formation of the iminium ion I. Upon light absorption, the electronically excited state $\mathbf{I}^{*}$ oxidizes toluene to form the radical cation $\mathrm{V}$, which is deprotonated by the counteranion of the iminium ion (green circle). This irreversible step is essential to avoid an irreversible BET and delivers the benzyl radical VI. The ensuing stereocontrolled radical coupling with IV forges the stereocenter within product 2 .

In summary, we have documented a photochemical organocatalytic method for the direct stereoselective $\mathrm{C}-\mathrm{H}$ functionalization of feedstock chemicals, including toluene and xylene derivatives.

\section{ASSOCIATED CONTENT}

\section{S Supporting Information}

The Supporting Information is available free of charge on the ACS Publications website at DOI: 10.1021/jacs.8b05240.

Experimental procedures and spectral data (PDF)

\section{AUTHOR INFORMATION}

\section{Corresponding Author}

*pmelchiorre@iciq.es

ORCID $\odot$

Daniele Mazzarella: 0000-0001-7121-9796

Giacomo E. M. Crisenza: 0000-0003-0622-2862

Paolo Melchiorre: 0000-0001-8722-4602

\section{Notes}

The authors declare no competing financial interest.

\section{ACKNOWLEDGMENTS}

We thank MINECO (CTQ2016-75520-P), and the European Research Council (ERC 681840-CATA-LUX) for financial support. D.M. thanks H2020-MSCA-ITN-2016 (722591PHOTOTRAIN) for a predoctoral fellowship. G.E.M.C. thanks the Marie Skłodowska-Curie Actions for a postdoctoral fellowship (H2020-MSCA-IF-2017 795793).

\section{REFERENCES}

(1) Li, C. J.; Trost, B. M. Proc. Natl. Acad. Sci. U. S. A. 2008, 105, 13197.

(2) Fundamentals of Petroleum Refining; Fahim, M. A., Al-Sahhaf, A. T., Elkilani, A., Eds.; Elsevier Science, 2010.

(3) For reviews on $\mathrm{C}-\mathrm{H}$ activation and functionalization strategies, see: (a) Davies, H. M. L.; Du Bois, J.; Yu, J.-Q. Chem. Soc. Rev. 2011, 40, 1855 and related thematic issue. (b) Lyons, T. W.; Sanford, M. S. Chem. Rev. 2010, 110, 1147.

(4) For selected examples, see: (a) Liu, H.; Shi, G.; Pan, S.; Jiang, Y.; Zhang, Y. Org. Lett. 2013, 15, 4098. (b) Shimada, S.; Batsanov, A. S.; Howard, J. A. K.; Marder, T. B. Angew. Chem., Int. Ed. 2001, 40, 2168.

(5) Transition metal insertion into primary $\mathrm{C}\left(\mathrm{sp}^{3}\right)-\mathrm{H}$ bonds generally requires the use of directing groups: (a) Baudoin, $\mathrm{O}$. Chem. Soc. Rev. 2011, 40, 4902. (b) Giri, R.; Shi, B.-F.; Engle, K. M.; Maugel, N.; Yu, J.-Q. Chem. Soc. Rev. 2009, 38, 3242.

(6) (a) Neufeldt, S. R.; Sanford, M. S. Acc. Chem. Res. 2012, 45, 936. (b) Davies, H. M. L.; Morton, D. Chem. Soc. Rev. 2011, 40, 1857. (c) Dick, A. R.; Hull, K. L.; Sanford, M. S. A. J. Am. Chem. Soc. 2004, 126, 2300. (d) Zhao, S.-B.; Song, D.; Jia, W.-L.; Wang, S. Organometallics 2005, 24, 3290.

(7) For selected examples, see: (a) Wu, Y.; Choy, P. Y.; Mao, F.; Kwong, F. Y. Chem. Commun. 2013, 49, 689. (b) Aihara, Y.; Tobisu, M.; Fukumoto, Y.; Chatani, N. J. Am. Chem. Soc. 2014, 136, 15509. (c) Liu, H.; Laurenczy, G.; Yan, N.; Dyson, P. J. Chem. Commun. 2014, 50, 341. (d) Qrareya, H.; Ravelli, D.; Fagnoni, M.; Albini, A. Adv. Synth. Catal. 2013, 355, 2891. (e) Xiang, M.; Xin, Z.-K.; Chen, B.; Tung, C.-H.; Wu, L.-Z. Org. Lett. 2017, 19, 3009. (f) Ishida, N.; Masuda, Y.; Ishikawa, N.; Murakami, M. Asian J. Org. Chem. 2017, 6, 669.

(8) (a) Ohkubo, K.; Mizushima, K.; Iwata, R.; Souma, K.; Suzuki, N.; Fukuzumi, S. Chem. Commun. 2010, 46, 601. (b) Bloom, S.; McCann, M.; Lectka, T. Org. Lett. 2014, 16, 6338. (c) Zhou, R.; Liu, H.; Tao, H.; Yu, X.; Wu, J. Chem. Sci. 2017, 8, 4654.

(9) (a) Davies, H. M. L.; Jin, Q.; Ren, P.; Kovalevsky, A. Y. J. Org. Chem. 2002, 67, 4165. (b) Qin, C.; Davies, H. M. L. J. Am. Chem. Soc. 2014, 136, 9792.

(10) Silvi, M.; Melchiorre, P. Nature 2018, 554, 41.

(11) Stereoselective functionalization of acetonitrile: (a) Suto, Y.; Tsuji, R.; Kanai, M.; Shibasaki, M. Org. Lett. 2005, 7, 3757. (b) Kawato, Y.; Kumagai, N.; Shibasaki, M. Chem. Commun. 2013, 49, 11227. Stereoselective functionalization of ethers: (c) Davies, $\mathrm{H}$. M. L.; Hansen, T.; Churchill, M. R. J. Am. Chem. Soc. 2000, 122, 3063. (d) Weldy, N. M.; Schafer, A. G.; Owens, C. P.; Herting, C. J.; VarelaAlvarez, A.; Chen, S.; Niemeyer, Z.; Musaev, D. G.; Sigman, M. S.; Davies, H. M. L.; Blakey, S. B. Chem. Sci. 2016, 7, 3142. Stereoselective functionalization of cycloalkanes: (e) Davies, H. M. L.; Hansen, T. J. Am. Chem. Soc. 1997, 119, 9075. 
(12) (a) Silvi, M.; Verrier, C.; Rey, Y. P.; Buzzetti, L.; Melchiorre, P. Nat. Chem. 2017, 9, 868. (b) Verrier, C.; Alandini, N.; Pezzetta, C.; Moliterno, M.; Buzzetti, L.; Hepburn, H. B.; Vega-Peñaloza, A.; Silvi, M.; Melchiorre, P. ACS Catal. 2018, 8, 1062. (c) Woźniak, Ł.; Magagnano, G.; Melchiorre, P. Angew. Chem., Int. Ed. 2018, 57, 1068.

(13) Yoshida, J.; Kataoka, K.; Horcajada, R.; Nagaki, A. Chem. Rev. 2008, 108, 2265.

(14) Merkel, P. B.; Luo, P.; Dinnocenzo, J. P.; Farid, S. J. Org. Chem. 2009, 74, 5163.

(15) De Nicholas, A. M.; Arnold, D. A. Can. J. Chem. 1982, 60, 2165.

(16) For reviews on PCET processes, see: (a) Warren, J. J.; Tronic, T. A.; Mayer, J. M. Chem. Rev. 2010, 110, 6961. For an application of concerted PCET in enantioselective catalysis, see: (b) Rono, L. J.; Yayla, H. G.; Wang, D. Y.; Armstrong, M. F.; Knowles, R. R. J. Am. Chem. Soc. 2013, 135, 17735.

(17) For a study on the ability of iminium ion counter-anions to act as a base, see: Lakhdar, S.; Mayr, H. Chem. Commun. 2011, 47, 1866. (18) NMR studies indicated that diphenylphosphoric acid is too weak to promote iminium ion formation, while the lack of reactivity with triflic acid is ascribable to the complete protonation of aminocatalyst $\mathbf{A}$ hampering condensation with 1a.

(19) For a discussion on the $\mathrm{Zn}$ (II) salt-mediated condensation of amines and aldehydes, see: (a) Zinc Catalysis: Applications in Organic Synthesis; Enthaler, S., Wu, X.-F., Eds.; Wiley-VHC, 2015; pp 156162. For a report exemplifying the ability of Lewis acids to exchange counter-anion in iminium ion-mediated reactions, see: (b) Duce, S.; Mateo, A.; Alonso, I.; García Ruano, J. L.; Cid, M. B. Chem. Commun. 2012, 48, 5184.

(20) The site selectivity is ascribable to steric factors hampering the deprotonation at the tertiary C- $\alpha$ carbon of 3 . This scenario is congruent with the lack of racemization of the unreacted 3 , recovered after the photochemical process, and the low reactivity of tertiary benzylic substrates (see page S30 in the Supporting Information).

(21) Evans, S.; Smith, J. R. L. J. Chem. Soc. Perkin. Trans. 2 2000, 1541. 